\title{
The power of smart solutions: knowledge, citizenship and the datafication of Bangalore's water supply
}

\author{
Linnet Taylor ${ }^{1}$ and Christine Richter ${ }^{2}$
}

\begin{abstract}
While plans to develop "smart cities" are gathering pace across the world, we know little about the ways in which the discourses of datafication, smartness, and big data play out in material contexts of urban development, including utility and resource management. In this paper, we explore this intersection in the case of Bangalore's water supply, where IBM in alliance with the Bangalore Water Supply and Sewerage Board (BWSSB) is implementing a water-flow sensor network and geographic database system under the label of "big data for water supply." We illustrate how the BWSSB-IBM approach narrows down the complex field of water provision to a question of water in- and out-flow measurements and the monitoring of BWSSB ground personnel. In theoretical terms, we discuss the ways in which these processes constitute both particular claims to knowledge, and the redefinition of citizenship as consumption.
\end{abstract}

\section{Introduction: linking datafication, development and citizenship}

Processes of datafication (Mayer-Schönberger et al. 2013) have spread to the developing world over the last decade as data analytics firms such as IBM, Cisco and Accenture have globalised their marketing of smart technologies and services. In their move into emerging markets the firms have focused particularly on the swift growth in cities (Datta 2015), marketing 'smart city' products such as data management systems for utilities and transport networks (the terminology of the smart city is currently badly defined (Greenfield 2013), but includes the application of digital and particularly

\footnotetext{
${ }^{1}$ Tilburg University, Netherlands

${ }^{2}$ University of Twente, Netherlands
} 
sensing technologies to urban development problems). In doing so, they have drawn on discourses of big data which frame the creation of smart environments as ways of creating efficiency and security, but also of establishing and streamlining power relations between the client (municipal authorities) and the city's users (citizens) (Greenfield 2013).

This engagement between multinational technology firms and developing-country governments or municipalities represents a new mode of development practice and discourse, one characterised by the business of gathering and selling data, termed informational capitalism (Cohen, 2013; Taylor \& Broeders, 2015). Also characterised as 'entrepreneurial urbanisation' (Datta, 2015), the creation of smart cities offers business advantages for those who can engage with the new discourses of datafication, but correspondingly disempowers others and reinforces inequality. The datafication of urban systems also, we will argue, has impacts on citizenship by making it easier for the authorities to track, monitor and surveil people's interaction with the bureaucratic and material systems of the city, for example identifying and excluding those classified as free-riders, who use water outside the official schedule, and rewarding particular types of consumer behaviour.

Public-private partnerships are nothing new in development, nor are the extractive dynamics that tend to characterise them (Author et al. 2015), but the new smart-city PPPs have the potential to create new dynamics in urban governance both in terms of the control and use of knowledge and in terms of what is conceived as useful knowledge (Author \& Author 2015). What can be seen emerging from these new partnerships is a struggle between Mode I and Mode II types of knowledge production (Pfeffer et al. 2013), i.e. between authoritative knowledge produced by the scientific establishment and knowledge developed collaboratively. The power to define knowledge is also related to that of defining citizenship: who counts in the datafied city is determined, to a great extent, by what is counted.

This paper will examine the struggle over what is counted, and who is included, in the context of Bangalore's urban water system and the city authorities' engagement with data technologies in order to reorganise and document the system's functioning. IBM, as a contractor to the Bangalore 
Water Supply and Sanitation Board (BWSSB), has recently integrated a 'smart' water sensor system to regulate and control water distribution via digital sensor data and geographic information systems (GIS) technologies. We look at how the introduction of 'big data' and 'smart solutions' introduces new actors and power dynamics both in terms of 'who counts as a citizen' and 'what counts as knowledge'.

In doing so, we follow the logic of Cherlet (2014: 1) who developed the term 'epistemic determinism' to describe the way that certain sources of information (including the quantified, largescale and digitally generated) become considered more reliable, accurate, and truthful than others. While the language of big data and smart solutions is in use in cities worldwide, we still know relatively little about the kind of work these discourses do in material contexts, and lack empirical studies of how the notions of big data and smart solutions are being implemented, and to what effect, in cities across the world (Rabari et al. 2015). Our study explores the process of datafication and the resulting effects on citizenship and the power over knowledge, taking into account the forces of business advantage, informational capitalism and power relations within the city's bureaucratic apparatus.

The paper is structured as follows: the next section explains the background and history of Bangalore's water problem and what has led to the current technological approach and the particular public-private configuration of actors trying to address it. Next, we break down the problem of insufficient water supply into its different elements: the mechanical, bureaucratic, social and political. We analyse how these are being smoothed out by an approach involving datafication and automation, and what elements of the problem this approach is likely to address. Finally, we draw conclusions about the implications of this approach for citizenship in Bangalore.

A note on methodology: this study is based on interviews conducted during 2014 while Bangalore was in transition to a new water management system developed by IBM. It also draws on online and offline media commentary from India for the same period. With a snowball sampling method starting from the Centre for Internet and Society (CIS) in Bangalore, we contacted organizations and individuals involved in water provision and the implementation of new digital data and related technologies. Interviews took place during a one-month visit to Bangalore by the second 
author in October 2014, and follow-up via phone interviews by the first author in early 2015. Interviews were complemented by field and office visits, and by workshop discussions with research Our study places less focus on water governance actors and practices dominant in Bangalore's high growth areas of the periphery, which form the focus of extensive research by Ranganathan (2009, 2011, 2014a, 2014b). Instead, our discussion reflects a 'perspective from the centre' in terms of both urban geography and institutional arrangements in the context of water provision. The actors we have targeted in our research (see table 1 below) can be roughly categorized into those close to the official mandate of providing water (namely the Bangalore Water Supply and Sanitation Board, or BWSSB; IBM and NextDrop, a small start-up company) and those operating outside the official mandate, including activist groups and neighbourhood associations (Citizen Matters, Biome Environmental Solutions (Biome), Namma Bengaluru Foundation (NBF), Arghyam, resident welfare associations and tanker water providers.

In their search for solutions to water provision different actors put emphasis specifically on data and related technologies, on administration and politics of urban water governance, or on both. Biome is an example of a company deploying new data technologies to address various urban development challenges, especially related to environmental management, including, but not exclusively, the use of groundwater sources in peripheral areas of urban growth. NBF and Citizen Matters, on the other hand, put relatively little emphasis on data driven solutions, but engage in the water provision scene through political and legal channels. Both IBM's and NextDrop's approaches are driven by and focused on solutions based in the development of digital data technology.

Perspectives on both problems and solutions to Bangalore's water supply and distribution differ across actors, their agendas, and alliances between them. However, the different ways in which they are addressing it demonstrate some problems with big data and smart approaches as a way of creating sustainable solutions to urban problems. 


\section{Bangalore, its water supply and datafication}

Bangalore's growth in the past decades has been immense; from 400,000 people in India's postindependence time to 8.5 million people today. A multiplicity of actors and shifting actor alliances has emerged over the past decades making for a complex organizational situation in two fields: the material context of water provision in the city and the field of new data technologies around water provision. The city is large, it has a substantial informally settled population, and therefore water rights, allocation and distribution are contested. This contestation has given rise to the involvement of a diverse group of actors in the water governance landscape, ranging from consultants to local think tanks and foundations.

The history of datafication in Bangalore goes back to far beyond the current smart city paradigm. It is the capital of the state of Karnataka, India's leader in e-government since 1987, but long before this was hailed by Jawaharlal Nehru, India's first prime minister, as the city of the future. The most prominent manifestations of Bangalore's role as information technology hub in urban morphology and development are Electronic City in the southeast of the city, and the International Tech Park connected via a 25-km IT corridor to Bangalore's centre. In addition, the 'Silicon Valley of India,' as the city is sometimes called, has drawn many non-resident Indians from the Californian Silicon valley back to their homeland along with ideas, financial resources, and political connections, who influence IT implementation efforts across different urban development domains, including land administration and transportation planning, as well as national level guided projects such as Aadhaar ${ }^{3}$, the Unique Identification Number project. It comes as little surprise that Bangalore is listed among the nearly 100 cities to become 'smart cities' according to India's Prime Minister Narendra Modi's announcements (Times of India, 2015). Alongside young IT professionals working for companies like InfoSys, IBM, or CISCO, in the past ten years the city has also become centre for an increasing number of young computer scientists, academics, and activists advocating government transparency and open

\footnotetext{
${ }^{3}$ Aadhaar is a Hindi word meaning "base" or "foundation." Here it refers to a project by the Unique Identification Authority of India, which seeks to issue unique digital ID numbers to all Indian citizens.
} 
data, citizen-driven digital data collection and mapping, as well as a critical engagement with the potential risks of urban development increasingly driven by the discourse of 'smart' cities and 'big' data solutions, including the risks of surveillance of citizens, privacy concerns, and continued land dispossession in the name of real estate development.

In this way, IT-related real estate and urban development interests have become part of the map of citizenship and socioeconomic hierarchy in Bangalore. They are amongst the main water users, especially of groundwater in the periphery; and close ties between the material contexts of water and land governance (Ranganathan 2014a, 2014b) raise further doubts regarding both the feasibility and the politico-economic implications of fast solutions to urban development challenges promised by 'smart approaches,' such as the provision and distribution of water.

BWSSB carries the official mandate to organize and maintain water supply, distribution, and sanitation networks in Bangalore, and as such occupies a central role in the water provision scene of the city. The board was founded in 1964 upon request by the World Bank to constitute an autonomous body responsible for water supply and sanitation (Bengaluru Water Supply and Sewerage Board 2014). BWSSB sources most of its water from the Cauvery River providing 900 million litres per day through ca. 500,000 pipeline connections in the Bangalore core area and in layouts planned and approved by the Bangalore Development authority, so called 'authorized' areas (Ranganathan 2009, Ranganathan 2014b). In terms of water supply, the institution's focus rests on maintenance and expansion of the water pipeline system. Given the legal cap on how much water Bangalore can use from the Cauvery River and a history of inter-state disputes over the river's resources (Pangare et al. 2006), in combination with the history of the institution's official mandate to provide river water via pipelines, BWSSB currently has three options to tackle the growing water demand of the city, according to a Biome interviewee. Through construction of sewage treatment plants, the reuse of wastewater has become one option. Second, water from local lakes is an augmentation option. However, the number and surface areas of lakes have been dwindling in past years due to urban development. A third issue BWSSB can seek to tackle is the so called 'water leakage' across the pipeline system. General discourse 
in the city has it that 30 to $50 \%$ (within this range the amount varies among different interviewees) of Cauvery water is lost from pipelines due to leakage caused by poor maintenance of pipelines as well as unofficial syphoning of water. According to interviewee from Biome, 'the first thing BWSSB will look at is the 30 to $40 \%$ thing. So, you have to look at the IBM project in that context.'

According to a senior IBM official in Bangalore who is an expert on smart city development, the company's engagement with BWSSB started around 2011/2012. In Bangalore IBM occupies a large building on the Embassy Golf Links compound on Domlur Ring Road. The compound is gated and security measures are high. The hallways of the office building are decorated with posters displaying the labels 'smart infrastructure,' 'smart business,' 'smart cities.' But IBM is not alone in the endeavour of finding and implementing 'smart' solutions. One of its main competitors is $\mathrm{CISCO}$ and it was around the time of our interviews that the media announced that CISCO would be in charge of implementing smart technologies in Electronic City, an IT complex at the south-eastern fringe of the city.

The IBM interviewee explained that when starting their engagement with BWSSB there were a lot of areas identified as problematic challenges for the BWSSB. One was energy management. A second was the management of complaints by current and potential customers of water, specifically how citizens can complain and how complaints and follow-up could be tracked more effectively. And a third main issue discussed was that of 'equitable water supply.' It is the latter issue that IBM focused on in its collaboration with the BWSSB. Within this larger problem of 'equitable water supply,' the BWSSB wanted to focus on two specific issues according to the same IBM interviewee, namely to find a solution to distribute water equitably across the existing pipeline system by monitoring in- and outflow of water and to manage and monitor the work of the valve men, employees of the BWSSB, who open and close valves at given points in time during the day and night to supply their respective area with water. Initially 118 bulk flow meters were installed to monitor water flow across distribution areas by a different vendor in contract with the BWSSB. Later IBM partnered with this vendor and built a GIS database to map bulk flow meters, and ground level reservoirs as a basis for GIS-based visualization, and subsequently started to use the increasing amounts of data for various analytics to 
measure and monitor water flow and to provide engineers with real-time information about the closing and opening of valves by the valve men. At the time of interviews (October 2014) 218 bulk flow meters were in place; and the plan, according to IBM, is to increase the network to 800 sensor meters.

\section{Who counts as a citizen in Bangalore's datafied water system?}

Although not articulated within the project's design or by the actors involved, the datafication of the BWSSB's operations has an important impact on citizenship. By categorising and monitoring flows of water, the system also inevitably determines who may and may not access water and on what terms. Our research shows that each actor involved had a different definition of what was equitable with regard to water provision, and specifically which groups equitable provision should benefit.

For example, IBM differs from other actors in its focus specifically on piped water provision and thus Bangalore's core area. For IBM, the smart sensor project would provide 'near-real-time monitoring and advanced analytics [to] reduce waste and deliver equitable water services' to the water-thirsty city (IBM 2014b). In contrast, for the local media the project was designed to create 'equitable distribution' of water across the city (e.g. Economic Times, 2014). The problem of water leakage, one of the main foci for the collaboration between BWSSB and IBM, helps to demonstrate the different understandings of what constitutes 'equitable water supply,' and by connection, whether citizens should be defined as consumers of water, as customers of BWSSB, or otherwise. The senior IBM official we interviewed explained that 'we are looking for 'equitable' from the perspective of water board or agency', and from this perspective, the problem is one of reducing the share of Bangalore's water that goes missing from the pipeline system - 45 per cent according to IBM (2014a), and over 50 per cent according to another interviewee - which is mainly classified as a 'leakage' problem. Our interviews with a range of actors in Bangalore's water provision domain demonstrate that the meaning of the concepts of leakage and equitability is highly dependent on contextual factors, both material and 
social, but that the project's big data discourse (Economic Times 2014) conflates and transforms into a problem of information processing.

Materially, an interviewee from a non-governmental organisation noted that much leakage is technical and due to an old and malfunctioning pipeline system, whose pipes are put under extra stress by an intermittent supply schedule which creates regular vacuums that weaken them. They also point to organisational problems that make it difficult to identify and deal with leakages: a lack of capacity amongst agencies dealing with water due to a lack of professionalisation, and to the frequent transfer of officials between domains and a consequent lack of expertise amongst those managing the system. The interviewee also noted that a large proportion of leakage was commercial, i.e. in the sense of financial losses ensued by BWSSB. Many living in informal or new settlements are not served by the city's water services, and therefore have to pay for delivery by tankers from private companies. These tankers often source their water from the city's pipes, so that at least part of the leakage problem represents a complementary, but officially illegitimate, mode of provision.

Meanwhile, for those within reach of the pipes getting a legal connection is complicated. It involves a wait of two to three months, fees, and paying for a water meter. Yet the metered usage billed by the BWSSB is much higher than the amount of water a household is receiving because much of leak out through the damaged pipes. All this represented a significant disincentive to get a legal connection and a strong incentive to connect informally to the system. Those with such an 'illegal' connection also call on powerful interests to prevent the water authority from cutting them off. Another nongovernmental interviewee explained that 'nonpayment of bills and legalisation of illegal connections are a political economy problem. But you don't want to cut them off because then you start to hear from the politicians.' In this way, irregular provision becomes formalised as part of the system while simultaneously being classified as 'theft' or 'leakage' in official terminology. Thus, for Bangalore residents with piped water leakage is a problem of infrastructural inadequacy. For those without a connection, commercial leakage is the only way they can get water. For those paying for tanker deliveries, leakage is a necessary supplement to provision. And for the BWSSB's own 
operators, leakage is a negotiated, socially embedded necessity that - in contrast to IBM and BWSSB's objective of establishing a positive standard of equity - instead performs a remedial function by reducing the established inequity in access to water. From the perspective of the BWSSB-IBM alliance around smart technology the problem to be addressed is one of controlling information, monitoring the pipeline infrastructure, and - as the next section further elaborates - of the controlling and monitoring of human resources. From the perspective of citizens of Bangalore, however, one's proximity to the piped water system defines one's citizenship in terms of water provision, a spatial and economic divide that is reified and reinforced by datafication.

Even for those within the BWSSB's piped water system, citizen status must be negotiated. For those with a legal connection, service is restricted to a few hours per day, up to three times per week, according to an interviewee who worked in an organisation that observed water provision. This intermittent water provision is centrally scheduled and locally implemented by 'valve men' - operators attached to specific neighbourhoods, whose job is to turn the water supply on and off for their area. Electricity outages, however, mean that scheduled supply often cannot happen since the system relies on electric pumps for water delivery. This leads to an informal system where residents 'tip' the valve man to provide this missing water outside the official schedule. It is this practice of informally making up missed water access that the new sensor system is primarily designed to stop. The sensors inform headquarters daily about actual water flow, enabling 'water engineers to see if valve timings have been followed correctly' (Merchant et al. 2014). An IBM executive confirmed that the new system is designed to control the autonomy of the valve men: 'the data gathered has a real-time component so that the BWSSB can tell if a valve has been closed on time ... they can question the valve men on a daily basis, which helps create behavioural change in them.

The conflict between the BWSSB's central office and the autonomous, locally-responsive function of the valve men underlines the tension between efficiency and equitability - and also shows that one of the main functions of the datafication project is to erase that distinction. A civil society 
representative argues that valve men are providing one interpretation of an equitable service that is now being brought into explicit conflict with more technocratic, datafied interpretations:

'You have to interpret data in the larger context of what this kind of human resource means to an institution. ... Valve men from the water company [provide water] unofficially. But everyone is gaining, and he takes a tip for doing it. The system is not recognising his ingenuity and rewarding him for that, so let the people reward him. When you talk about technologies and data, how do you use this data in the context of ground realities?' (interview with representative of an organization providing solutions for urban environmental protection and management, 15 October 2014).

The new smart sensor system created by IBM is designed to create organisational distance between central and neighbourhood-level logics of supply and demand: instead of face-to-face or phone encounters and negotiations between valve men, service station supervisors, and higher level BWSSB engineers, the valve-men, equipped with mobile phones, will instead get a popup they have to answer letting them know they must close the valve. There is some doubt as to whether this approach will work, however, according to other companies which are adopting different approaches to the same problem. NextDrop, for example, emphasises the need for close collaboration with the valve men in order to counteract the strong social incentive to obey the neighbourhood rather than the water board. It advocates continuous training and incentive structures, and for the need for a feedback system design that 'needs to be smart' in the sense that it is 'easy for them [valve men] to operate' (interview with NextDrop, 9 October 2014).

By seeking to remove the current system's nuances and points of negotiation and adjustment, the smart sensor system effectively reframes water from a right to a product, and the individual water user from citizen to consumer. It does this, however, without addressing either the technical problem of inadequate infrastructure or the commercial aspects of leakage that make the system both chaotic and responsive. Smartness in this context is a force that distances the users of a system from the ability to influence that system, to negotiate with it and each other, and to ultimately exercise citizenship 
rights such as the right to water from their city, to which they have contractual access. The following section examines the interplay between systemic smartness and claims to knowledge, and the ways in which the power to count and sort becomes inscribed in, and conveyed by, smart systems.

\section{What counts as knowledge with regard to water governance?}

The case explored in this paper points toward a common issue both in public-private partnerships involving data analytics, and also in the development field more broadly: that of solutionism (Morozov 2013), the search by technology developers for a problem that their system or process can become a 'solution' to. In the case of Bangalore's water supply there are multiple problems, some of which may be solvable with technical means, and others which are structural. These problems include demographic aspects such as rapid population growth and informal settlements that are not easily served by the existing system; formidable political challenges due to a multiplicity of formal and informal water governance arenas across the urban landscape; and also organisational and bureaucratic problems, especially in the form of administrative obstacles to organising formal water connections which contributes to the free-rider problem. Last but not least, there are problems deriving from the physical infrastructure weaknesses of a supply system whose hardware is old and prone to leaks, and which experiences frequent power outages so that people do not receive water as scheduled. The datafication of this system - partially based on more established technologies, such as GIS mapping and analyses, partially based on new big-data-driven technologies reliant on real-time, smart sensors - can be seen as situating a technical solution as the single answer to a complex and multifaceted problem-space.

By defining the 'water leakage problem' along the lines of weaknesses in the technical infrastructure and financial losses ensued due to a lack in oversight of in- and outflows of water, the system also effectively frames the BWSSB's management as 'end user' of the water system (Merchant et al, 2014) rather than individuals or households, and thus reframes the problem as one of 
information management rather than basic rights and needs. Despite the drawbacks of smartness as a way of understanding the realities of supply and demand driving the system's behaviour, from IBM's point of view, the production of digital data from the system constitutes value. The data the system produces in the course of its operation is transformed by IBM into portable knowledge: each system the firm designs and installs becomes part of its overall database of solutions and is a transferable resource that can be modified to address similar problems elsewhere. At an international 'smart cities' industry event, a presenter from IBM's cities program explained the Bangalore water solution's portability:

'We want to see how open your [water] platform can be to integrate and cooperate and connect with other platforms - transport, energy, etcetera [...] because one day I may lose my contract so I want to be able to extract my data and move it to another platform. Contracts with the city are not forever, so I need to be able to move to work on another service.' (IBM presentation, Smart Cities Event, 4 June 2015, Amsterdam Arena).

As well as solutions, IBM packages knowledge. The company's representatives refer to individual solutions such as Bangalore's as tools to convince cities that the firm should manage all their logistics, so that eventually 'every citizen could consume every service through one control centre', run by IBM.

Furthermore, datafication effectively redefines knowledge for its customers by moving the institutional and human elements of the system, namely BWSSB and IBM's decision-making process and actions, into the background and instead foregrounding facts and numbers. The volume of water flowing in a given period between one sensor and the next; the binary of whether a valve is open or closed, the readings on household water meters and the amounts demanded by the new online payment system all distance the individual from the provider and decrease the possibility of disagreement by providing a statement of water use based on digital feedback from the system.

Situated like a cork in a bottle at the end point of a complex and fluid set of problems, IBM's solution is characterised by a focus on managerial power, on the quantification of physical flows of 
water, and on the analysis and transmission of precise information about the timing and quantity of those flows. Many problems within the system of piped water provision incentivise local valve managers to behave autonomously in response to local needs and remuneration. This result, stemming from the whole complex of other problems, is one of the main water supply issues that IBM's solution addresses. The solution does so in a quantitative fashion by sensing and reporting how much water is flowing through the system and at what intervals, allowing managers to interpret whether or not valves are being opened and closed on schedule. Under conditions of water scarcity, frequent contamination and faulty infrastructure, this series of human pivot-points makes it possible to supply water in the first place - something the BWSSB-IBM smart approach may manage to counteract. It is still too early, however, to know whether these attempts will succeed, because the analogue knowledge of the valve operators forms a formidable barrier to the production of datafied knowledge.

\section{Conclusion: changing notions of knowledge and citizenship}

Rather than being locally generated and tailored to particular local needs, the development of a 'smart,' 'big data' approach to water distribution in Bangalore is part of a larger trend worldwide where multinational consultancies such as IBM use one utility sector as a practice ground for developing systems that can then be replicated and scaled for other utilities and other cities. This approach asserts that digital technology makes problem-solving approaches more transferable across contexts and space, and that this is in fact a strength of the big-data corporate approach. As a city manager you can now buy a solution, or at least a consulting process, that has undergone a proof-ofconcept stage in a high-profile, high-tech city. As much as an operational approach to urban problems, 'big data' in the urban governance context is a brand that sells services and products. We therefore argue that the managerial, quantitative and top-down approach that characterizes BWSSB-IBM's 'big data for water supply' project is both a result of, and driven by, the epistemic determinism that tends to accompany datafied solutions, and the idea of big data as providing a purer, more actionable form of knowledge (Cherlet 2014). 
Such an approach also creates externalities whose repercussions may shape the system in particular ways as it continues to evolve. The datafied approach to a problem such as water distribution involves collecting the maximum amount of data on all flows and recipients, in order to include some as consumers and exclude others as free-riders. To do this, the problem is defined from the point of view of 'citizens as consumers', namely those citizens who are consumers of pipeline water. This also recalls the way that datafication creates visibility amongst its subjects (Author et al. 2015), in contrast to the legibility (Scott 1998) created by traditional administrative methods such as surveys. Big data allows the manager to see the system and its operation in detail, but does not connect to the system's human participants in ways that allow for feedback or dissent.

BWSSB-IBM's system therefore reinforces the existing idea of the customer versus the freerider, and its corresponding implication that the right of citizens to water is somehow contingent on location or socioeconomic status.- This also means that many Bangalore residents cannot hold BWSSB accountable for their access to water because they are not 'consumers'. Those who can be held accountable by residents, for instance their local elected representatives, are already involved as actors in the problem-space of 'leaked water'. Conversely, if citizenship is equated with being a consumer of water rather than a user or rights claimant, then a large number of residents become excluded from de-facto citizenship due to informal living arrangements and connections. 


\section{References}

Author 2014. [Anonymized reference].

Author and Y. Georgiadou 2014. [Anonymized reference].

Author and D. Broeders 2015. [Anonymized reference].

Author, and Author 2015. [Anonymized reference].

Bauman, Z., D. Bigo, P. Esteves, E. Guild, V. Jabri, D. Lyon, and R.B.J. Walker 2014 . After Snowden: Rethinking the Impact of Surveillance. International Political Sociology, 8: 121-144. doi: 10.1111/ips.12048

Broeders, D. 2007. The new digital borders of Europe EU databases and the surveillance of irregular migrants. International Sociology, 22(1): 71-92.

Bengaluru Water Supply and Sewerage Board. 2014. Meeting the vital need for water A Golden $\begin{array}{llll}\text { Journey. } & \text { Last } & \text { accessed } & \text { February }\end{array}$ 2016.http://mybwssb.org/sites/default/files/ss/Bwssb\%20Brochure\%20English.pdf

Castells, M. 1996. The Rise of the Network Society, The Information Age: Economy, Society and Culture Vol. I. Oxford, UK: Blackwell.

Cherlet, J. 2014. Epistemic and technological determinism in development aid. Science, Technology \& Human Values, 39(6): 773-794.

Cohen, J. 2013. What Privacy is For. 126 Harv. L. Rev. 1904: 2012-2013.

Datta, A. 2015. New urban utopias of postcolonial India 'Entrepreneurial urbanization 'in Dholera smart city, Gujarat. Dialogues in Human Geography, 5(1): 3-22.

Economic Times. 2014. IBM to use Big Data for managing Bangalore's water supply. Last modified February 202014.2 http://articles.economictimes.indiatimes.com/2014-0220/news/47527361 1 bwssb-water-distribution-sewerage-board

Greenfield, A. 2013. Against the smart city. Do Projects.

IBM. 2014a. "Bangalore Water Taps IBM for Big Data Analytics". Last modified February 212014. https://www-03.ibm.com/press/us/en/pressrelease/43255.wss

IBM. 2014b. "Bangalore Water Supply and Sewerage Board". Last modified October 2014. http://www-03.ibm.com/software/businesscasestudies/hr/en/corp?synkey=W591880C05007W49

Mayer-Schönberger, V.; and K. Cukier 2013. Big data: A revolution that will transform how we live, work, and think. Houghton Mifflin Harcourt.

Merchant, A., MS Mohan Kumar, P. N. Ravindra, P. Vyas, and U. Manohar 2014. Analytics driven water management system for bangalore city. Procedia Engineering 70 (2014): 1137-1146.

Times of India. 27 August 2015. Full List of 98 Smart Cities. Last accessed February 182015. http://timesofindia.indiatimes.com/india/Full-list-of-98-smart-cities/articleshow/48694723.cms 
Morozov, E. 2013. To save everything, click here: Technology, solutionism, and the urge to fix problems that don't exist. Penguin UK.

Nair, J. 2005. The Promise of the Metropolis - Bangalore's Twentieth Century. Oxford University Press.

Ouchi, W. G. 1977. The relationship between organizational structure and organizational control. Administrative science quarterly (1977): 95-113.

Pangare, G., V. Pangare, and B. Das 2006. Springs of Life: India's Water Resources. Academic Foundation.

Rabari, C., and M. Storper 2015. The digital skin of cities: urban theory and research in the age of the sensored and metered city, ubiquitous computing and big data. Cambridge Journal of Regions, Economy and Society 8: 27-42.

Ranganathan, M. 2009. Piped Water Supply to Greater Bangalore: Putting the Cart before the Horse? Economic and Political Weekly XLIV(No 33, August 2009), 53-62.

Ranganathan, M. 2011. The Embeddedness of Cost Recovery: Water Reforms and Associationism at Bangalore's Fringes. In Urban Navigations - Politics, Space and the City in South Asia, edited by J.S. Anjaria \& C. McFarlane, 165-190. Routledge.

Ranganathan, M. 2014a. Paying for Pipes, Claiming Citizenship: Political Agency and Water Reforms at the Urban Periphery. International Journal of Urban and Regional Research 38(2), March 2014: 590608.

Ranganathan, M. 2014b. 'Mafias' in the Waterscape: Urban Informality and Everyday Public Authority in Bangalore. Water Alternatives 7(1): 89-105.

Scott, J. C. 1998. Seeing like a state: How certain schemes to improve the human condition have failed. New Haven: Yale University Press.

Shearmur, R. 2015. Dazzled by data: Big Data, the census and urban geography. Urban Geography, DOI: $10.1080 / 02723638.2015 .1050922$. 


\begin{tabular}{|c|c|c|}
\hline $\begin{array}{l}\text { IBM's Program Director } \\
\text { Smarter Cities (with public } \\
\text { relations officer) } \\
\text { Followup interview with } \\
\text { Program Director, January } \\
\text { 2015) } \\
\text { NextDrop (interviews in } \\
\text { October } 2014 \text { and January } \\
\text { 2015) } \\
\text { Citizen Matters } \\
\text { Namma } \\
\text { Bengaluru Foundation } \\
\text { BIOME } \\
\text { Arghyam } \\
\text { Long-time Bangalore resident, } \\
\text { journalist and environmental } \\
\text { activist } \\
\text { Representative of a resident } \\
\text { welfare association (with } \\
\text { translator) }\end{array}$ & $\begin{array}{l}\text { Office visits and work } \\
\text { presentation at NextDrop } \\
\text { Bangalore office } \\
\text { Visit to BWSSB service station } \\
\text { enrolled in NextDrop's } \\
\text { initiative and neighbourhood } \\
\text { walk with valve man } \\
\text { Visit to Jakkur Lake } \\
\text { development area and STP }\end{array}$ & $\begin{array}{l}\text { Discussions with researchers in } \\
\text { information systems and } \\
\text { geography at IIITB, IIMB, CIS } \\
\text { End-of-visit presentation and } \\
\text { discussion of preliminary } \\
\text { interpretations with CIS } \\
\text { researchers } \\
\text { Discussions with researcher at } \\
\text { Fields of View }\end{array}$ \\
\hline
\end{tabular}

